\title{
Length of Counseling Sessions and the Amount Of Relevant Information Exchanged: A Study in Peruvian Clinics
}

By Federico R. León, Rosa Monge, Adriana Zumarán, Ingeborg García and Alex Ríos

\begin{abstract}
Context: Time constraints have been implicated in family planning providers' inability to offer comprehensive counseling to their clients. It is important for providers to know whether lengthening counseling sessions increases the amount of relevant information imparted to clients.

Methods: Twenty-eight women were trained to pretend to solicit an effective method and to opt for the injectable contraceptive at 19 clinics in urban areas from a national sample of Ministry of Health facilities in Peru. Each clinic was visited on different days by six of these "simulated clients," for a total of 114 cases. For each visit, the woman recorded on a 46-item checklist the topics discussed by the provider and estimated the duration of the counseling session.

Results: Providers dedicated anywhere from two to 45 minutes to counseling. The amount of information given that was relevant to the client's choice significantly increased, by $43 \%$, when the session length went from 2-8 minutes to 9-14 minutes. However, further improvements in the amount of useful information exchanged were trivial and nonsignificant when session lengths extended beyond 14 minutes. At any duration, many pieces of information that should have been exchanged had not been. Offering a wide range of contraceptive options took up most of the consultation time and was highly correlated with session length. Discussion of the chosen method's side effects and screening for contraindications did not vary by session length.
\end{abstract}

Conclusions: Counseling sessions longer than 14 minutes confer little advantage in terms of effective counseling for women who choose the injectable. It is important that providers use the available time more efficiently; that they be more practical in assessing clients' needs; and that they avoid providing too much information about irrelevant methods. They should focus on the method chosen by the client and address that specific method in greater depth.

International Family Planning Perspectives, 2001, 27(1):28-33 \& 46

$\mathrm{T}$ he concept of "informed choice" in family planning counseling implies that providers assist clients in selecting the method that best satisfies their needs, and that clients leave the session knowing about the side effects of their chosen method and how to use it safely and effectively. ${ }^{1}$ Worldwide, however observational findings suggest that actual counseling is far from meeting these requirements.

Audiotaped counseling sessions in Kenya, for example, revealed that only $57 \%$ of clients receiving the injectable and 32\% of those getting the pill were provided with information on their method's side effects. ${ }^{2}$ A situation analysis of Nairobi clinics showed that fewer than $50 \%$ of new clients were provided with information on contraindications to or side effects of their chosen method. ${ }^{3}$ Further situation analyses conducted in 12 African countries indicated that the percentage of clients informed about both how to use their method and its potential side effects ranged from lows of $5 \%$ in Tanzania and 22\% in Burkina Faso, to highs of $64 \%$ in Kenya and $68 \%$ in Botswana. ${ }^{4}$ In a similar study conducted in Ecuador, Uganda and Zimbabwe, fewer than $75 \%$ of clients in each country were given any information about the contraceptive method they received. ${ }^{5}$

Results are no different when the specific content of counseling is examined. For example, to probe how well clients were being counseled about when and how to switch methods, a study carried out in the coastal province of Santa, Peru, used simulated clients who had recently initiated pill use and who complained of headaches. Of the 54 Ministry of Health providers who were approached, more than $25 \%$ failed to tell the client that the headaches might be a side effect of pill use, and more than $30 \%$ did not tell her that they might disappear shortly. ${ }^{6}$ In a similar study based on a national sample of 25 hospitals and 74 clinics in Ecuador, $47 \%$ of providers failed to tell the client that her headaches might be a side effect of the pill, and $61 \%$ neglected to inform her that they might go away with time. ${ }^{7}$

When confronted with such evidence of incomplete counseling, providers generally attribute their shortcomings to causes beyond their control. In rural areas of
Peru, for example, some nonprofessional Ministry of Health personnel explained that they had not been trained, while others were reluctant to give full information about a method because they doubted that clients would understand its mode of action, or because they did not want to scare off the client with talk about side effects. ${ }^{8}$ In urban areas of Peru, providers responding spontaneously to open-ended questions about delivery problems cited overscheduling and the resulting lack of time as the main reason why providers could not provide proper counseling. ${ }^{9}$

While pointing to time constraints is intuitively appealing to explain why only limited information is exchanged, this may only be a rationalization on the part of providers. The relationship between the duration of a counseling session and the amount of information exchanged needs to be objectively confirmed. Such empirical evidence, whether it confirms or refutes the time-constraint explanation, has important implications. This article presents the results of a study that gathered such empirical evidence and then highlights the practical implications of the findings.

\section{Methodology}

Selection of Clinics

This study is part of a larger evaluation project that used a stratified random sampling of facilities operated by the Peruvian Ministry of Health, ${ }^{10}$ which is the primary provider of family planning in the country. A total of 172 clusters, known as reporting units, reported complete service delivery data to the Ministry's family planning program in 1998.

Federico R. León is program associate with the Frontiers in Reproductive Health program of the Population Council, Lima, Peru. At the time this research was conducted, Rosa Monge was a consultant, Adriana Zumarán was an intern, Ingeborg García was an intern and Alex Ríos was a research assistant, all at the Population Council, Lima. The authors thank Lucy López for her comments on the study tools, Jorge Parra for his help in facilitating access to the health centers and John Townsend and Cynthia Green for their useful comments on earlier drafts of this article. The research upon which this article was based was made possible by funding from the U.S. Agency for International Development (USAID) under cooperative agreement HRN-A-00-98-0012-00 with the Population Council. The opinions expressed herein are those of the authors and do not necessarily reflect the view of USAID. 
These reporting units were stratified into three categories by the number of contraceptive sterilizations-both tubal ligations and vasectomies-performed in that year. We ranked the units by their sterilization caseload because the larger evaluation project paid particular attention to provider compliance with recent Ministry of Health norms pertaining to sterilization services. (It should be noted that sterilization was legalized as a contraceptive method in Peru only in 1995.) In this study, reporting units performing an intermediate number (40-149 procedures) were chosen for sampling.

Within this intermediate category, the reporting units were weighted by the number of family planning consultations provided during the year. Nineteen of these units were randomly selected, with the largest health center from each being chosen for the study. Five of the centers were in the department of Lima, and the other 14 were located in urban areas of the departments of Ancash, Arequipa, Ayacucho (two centers), Huánuco (three centers), Ica (two centers), La Libertad (two centers), Pasco, Piura and Puno.

\section{Service Test}

Our study used an offshoot of simulated client methodology called the "service test," in which the researcher controls the client profile and focuses observations on very specific provider behavior. ${ }^{11}$ This type of instrument avoids the problems of subjective judgment and the attendant low reliability associated with evaluating a wide range of behaviors.* The service test instrument incorporates a full profile for the simulated client; a system to recruit and train people to act as clients seeking services, and to use this specific profile in interactions with providers; and a checklist of provider behavior items requiring yes-no responses. Since the simulated client's individual situation and needs are known, the checklist can focus on very specific provider behaviors (e.g., "Did the provider ask you how you were using the rhythm method?").

Healthy women aged 20-30 with one child and from a variety of ethnic backgrounds were recruited through institutional and personal contacts to act as clients of family planning services. They were selected based on standardized tests of general cognitive ability, immediate memory and family planning knowledge. During training, we evaluated candidates' ability to project the specific client profile and to use the corresponding checklist. A few were dismissed during or after the training because they would not consent to having a pelvic examination, or were found to have medical conditions that would contraindicate use of the injectable (the method that the simulated candidates were supposed to choose).

We adjusted the client profile and corresponding checklist during training. The candidates selected to perform as clients role-played visits to facilities in the training classroom and later sought services at several health centers in Lima as part of their training. These women were paid for their work and any expenses they incurred were reimbursed. (Although the Ministry of Health distributes contraceptives free of charge, some of its facilities charge clients for the consultation.)

\section{Data Collection and Instrument}

A total of 28 women who agreed to pose as clients were hired and these women made an average of 4.1 visits to a ministry facility (range of 3-8 visits) in June and July 1999. Each of the 19 health centers that made up the sample was visited on different days by six of these simulated clients, which yielded a total of $114 \mathrm{ob-}$ servations. The simulated clients were instructed to respond to inquiries about their reproductive intentions by saying they wanted to postpone pregnancy. When asked about their current contraceptive use, they were to reply that they were relying on rhythm, but that they no longer felt secure because they had become pregnant while using it in the past and now wanted a more effective method.

The simulated client profile indicated that the client lacked experience with other methods and that she would reject the pill and the IUD on various grounds. The women were to reject condoms, citing their partner's unwillingness to use them regularly. Their choice of a method, made on practical grounds, was to be the quarterly injectable, depot medroxyprogesterone acetate (DMPA) - the method most frequently requested in Ministry of Health facilities in $1998 .^{12}$

When asked about her menses, the simulated client was to say that she was in the fourth day of menstruation. This response was devised to show the provider that she was not pregnant, since a pregnancy would contraindicate most methods. The women were instructed to submit to a pelvic exam if the provider required it. (So that a physical exam would not "give away" a simulated client, a client whose provider insisted on the exam was instructed to explain that she had just washed herself prior to the visit and that she usually had only sporadic spotting on the fourth day of her period.)

Simulated clients were carefully trained to project the profile of a healthy woman with no contraindications to the use of DMPA. This profile indicated that she had had her last Pap smear six months ago. If the consultation progressed to the point where the provider was ready to administer the injection, the simulated client was to indicate that she wanted to consult with her husband first, thank the provider and leave.

The simulated clients registered their observations on a yes-no checklist that contained 46 items of expected provider information-exchange behaviors in the following eight areas: general questions asked by the provider, including the offer of a pelvic exam (seven items); range of contraceptive options offered (eight items); instructions in the use of DMPA (four items); information about the injectable's mechanism of action (two items); screening questions for contraindications to DMPA use (six items); side effects of the injectable and warning signs (six items); information and advice on the use of barrier methods (nine items); and follow-up questions on the communication process (four items).

We added the nine items on barrier methods because at the end of her consultation, the client was to avoid actually receiving an injection by citing the need to consult with her husband first. The provider was then expected to discharge the client by doing one of three things: giving the client the DMPA vial so that when she is ready, she can ask a nurse somewhere else to apply the injection; giving her a prescription so that she can purchase the injectable and receive the injection in a pharmacy when she is ready; or scheduling an appointment for her to return to the facility to receive the injection there. Thus, the provider was expected to advise her to use barrier methods in the meantime and to instruct her in their use.

When the counseling session was completed, the client left the premises, filled in the items on the checklist and entered her observations on an open-ended form. Supervisors debriefed each simulated client after her first clinic visit to ensure that she was correctly projecting the client profile and that she was filling out the checklist properly. A simulated client performed her

\footnotetext{
*For example, broad questions such as "Did the provider give you a choice of methods" - with response ratings of full (5), wide (4), moderate (3), narrow (2) or none (1) reveal very little about the actual choice of methods offered to clients. (See: León FR, Quiroz G and Brazzoduro A, The reliability of simulated clients' quality-of-care ratings, Studies in Family Planning, 1994, 25(2):184-190.)
} 


\begin{tabular}{|c|c|c|}
\hline Behavior & $\begin{array}{l}\% \\
(\mathrm{~N}=114)\end{array}$ & Correlation \\
\hline \multicolumn{3}{|l|}{ General questions asked or action taken by provider } \\
\hline How old is client & 96 & -.11 \\
\hline How many children does she have & 96 & -.04 \\
\hline Does client want more children & 7 & $.19^{*}$ \\
\hline What methods has client used/is she currently using & 82 & -.01 \\
\hline How was client using the rhythm method & 12 & .11 \\
\hline What was date of last menstruation/whether pregnancy is suspected & 97 & .02 \\
\hline Performed or wanted to perform pelvic exam & 3 & .07 \\
\hline \multicolumn{3}{|l|}{ Method options offered or action requested by provider } \\
\hline Rhythm & 24 & .16 \\
\hline Condoms & 82 & $.27^{*}$ \\
\hline Vaginal tablets & 79 & $.28^{*}$ \\
\hline Pill & 95 & $.23^{*}$ \\
\hline DMPA & 88 & $.19^{*}$ \\
\hline IUD & 84 & $.20^{*}$ \\
\hline Tubal ligation & 26 & .14 \\
\hline Client asked to choose a method & 96 & .17 \\
\hline \multicolumn{3}{|l|}{ DMPA contraindications or related question asked by provider } \\
\hline Vaginal bleeding & 3 & -.03 \\
\hline Date of last Pap smear & 25 & .13 \\
\hline Family history of breast cancer & 5 & .01 \\
\hline Whether client knows how to do a breast exam & 7 & .14 \\
\hline Whether client has hard formations in the breast & 4 & -.07 \\
\hline Whether client has liver problems or yellow skin & 32 & -.06 \\
\hline \multicolumn{3}{|l|}{ DMPA mechanism of action told by provider } \\
\hline Injection would stop ovulation & 36 & .05 \\
\hline Cervical mucus would thicken & 10 & .14 \\
\hline \multicolumn{3}{|l|}{ DMPA use instructions given by provider } \\
\hline First injection administered in first five days of menses & 70 & .16 \\
\hline Injection administered in the buttocks & 46 & $.28^{*}$ \\
\hline Following doses given every 3 months & 93 & .15 \\
\hline Allowable window surrounding quarterly injection date is two weeks & 4 & -.12 \\
\hline \multicolumn{3}{|l|}{ DMPA side effects/warning signs told to client } \\
\hline Menstruation might stop altogether & 84 & .05 \\
\hline Menstruation may be irregular or spotting may occur & 77 & .06 \\
\hline Neither amenorrhea nor spotting is sign of illness & 44 & .06 \\
\hline Weight gain is possible & 37 & .07 \\
\hline Temporary infertility of 6-12 mos. might follow stopping method & 15 & .18 \\
\hline Abundant vaginal bleeding requires return visit & 12 & .01 \\
\hline \multicolumn{3}{|l|}{ Instructions on barrier methods given by provider } \\
\hline Condoms/vaginal tablets should be used while waiting for injection & 18 & .04 \\
\hline Coitus must be initiated with condom on & 47 & .10 \\
\hline Condom must be removed with penis still erect & 20 & .14 \\
\hline Each coitus requires new condom & 38 & $.21^{*}$ \\
\hline Vaginal tablet must be inserted 15 minutes before coitus & 54 & .13 \\
\hline Client must be prone for insertion of tablet & 29 & .15 \\
\hline Tablet is effective for one hour & 18 & $.20^{*}$ \\
\hline Each act of coitus requires new tablet & 25 & .05 \\
\hline Client must avoid douching during the hours following coitus & 24 & $.19^{*}$ \\
\hline \multicolumn{3}{|l|}{ Follow-up question asked or actions taken by provider } \\
\hline Asked whether client had understood & 23 & .14 \\
\hline Verified client's response by asking specific questions & 3 & -.02 \\
\hline Told client to return if she had any doubts & 12 & .02 \\
\hline Client given information leaflet & 27 & $.31^{*}$ \\
\hline
\end{tabular}

task knowing that a supervisor would later visit the facility and review the clinic history corresponding to her case and verify specific aspects of the consultation. Finally, since the sessions were not timed, project supervisors asked the simulated clients to estimate the duration of each counseling session. These estimates ranged from two to 45 minutes, with a median duration of 15 minutes.
To comply with ethics requirements, project supervisors made post hoc visits to providers to explain the nature of the study, to assure them that the data were confidential and to give feedback on the project. The providers' reactions to the project were generally positive. They showed an active interest in the feedback and said they would like to participate in similar projects again. With very few ex- ceptions, the providers had believed the simulated clients to be real clients. Only the providers in two small provincial clinics suspected the simulated clients because more women than usual had refused an injection by saying that they needed to consult with their husband.

\section{Results}

\section{Specific Provider Behaviors}

In at least $93 \%$ of the 114 simulated-client visits, providers asked questions about the client's age, number of children and date of last menstrual period; offered the pill as a contraceptive option; asked the client to make her own method choice; and told her that a DMPA injection needs to be repeated every three months (Table 1). DMPA was spontaneously offered in $88 \%$ of clinic visits, while in the remaining $12 \%$, the simulated clients requested the method themselves, once it was clear that the provider would not be offering it (not shown).

Guidelines established by the Peruvian Ministry of Health require that all new users of hormonal contraceptive methods be given a pelvic exam. ${ }^{13}$ However, only $3 \%$ of the visits involved either an actual exam or the offer to perform one. Moreover, in only $3-7 \%$ of visits were women asked if they wanted more children or if they had had vaginal bleeding, were told that the window of effectiveness surrounding their next quarterly injection was two weeks, were informed about signs and symptoms of breast cancer, or were asked specific questions by the provider to verify their comprehension of the counseling content.

Table 1 also presents the point-biserial correlation for each behavior-that is, the correlation between the dichotomous variable (of either the presence or absence of each behavior) and the continuous variable (of counseling session length, ranging from two to 45 minutes). A significant correlation $(\mathrm{p}<.05)$, denoted by a single asterisk, indicates that the longer the session length, the greater the likelihood that the item would be included in the consultation.

Of the 11 significant correlations, eight corresponded to topics unrelated to the chosen method, while only three were related to DMPA or relevant to its selection. This finding suggests that increased session time was used more to address other methods and issues than to expand on the attributes of the chosen method.

The barrier methods section of the checklist revealed an apparent contradiction in counseling content. While important proportions of the sessions involved instructions about initiating coitus with the condom on ( $47 \%$ ) and waiting $15 \mathrm{~min}$ - 
utes after inserting the vaginal tablet before coitus (54\%), in only $18 \%$ of cases did the provider instruct the client to use condoms or vaginal tablets until she was ready for her injectable hormonal contraception. This finding suggests that most providers talked in detail about barrier methods only early in the counseling process, before the client made her decision. Providers apparently did not, however, give specific information about barrier method use after being informed of the woman's decision to wait before accepting the injectable. This finding also suggests that most of the information about DMPA was also offered early in the counseling process.

The data collected by the simulated clients implies that providers were inefficient in the use of their time. For example, in $82 \%$ of visits condoms were discussed as a possible option, but in only $18 \%$ were they recommended as a barrier method to use while awaiting the injectable; thus, in a net of $64 \%$ of visits $(82 \%-18 \%)$ providers discussed condoms in considerable detail in the context of general options. Yet simulated clients were clearly not interested in this generalized information on condoms, and providers might have easily learned about clients' method preferences by asking about the attitudes of their partners who were unwilling to use them.

In $26 \%$ of cases, moreover, providers presented the option of female sterilization to a client who would not be receptive to it. Had providers asked clients about their reproductive intentions (only $7 \%$ asked the woman if she wanted more children), they might have excluded this option from discussion and put the consultation time to more effective use. In their discussions of potential options, $6 \%$ of providers talked about no method or just one, $10 \%$ mentioned 2-3 methods, 46\% 4-5 methods and 37\% 6-7 methods (not shown).

On the other hand, while $74 \%$ of providers excluded female sterilization from their discussion of methods, they did so using criteria that had nothing to do with the client's desires, since they had not asked about the client's reproductive intentions, including what she considered to be her ideal family size. We assume that providers concluded that sterilization was the wrong option simply because the client was young, was free of reproductive risk and had not reached her ideal family size.

\section{Areas of Information Conveyed}

The first column in Table 2 presents the average frequencies with which providers addressed the items in each of the eight content areas. For example, the simulated clients recorded that, on average, providers covered $56 \%$ of the generalquestions area (i.e., the result of averaging the seven percentages pertaining to the individual items in that area). Similar averages above $50 \%$ were calculated for the areas of method options (72\%) and instructions in DMPA use (53\%). In contrast, providers covered less than $25 \%$, on average, of the items in the following three areas-mechanisms of action of DMPA $(23 \%)$, screening for contraindications to DMPA $(13 \%)$ and communications followup $(16 \%)$.

Table 2 also presents the Pearson correlations between session length (2-45 minutes) and the sum of item scores (observed $=1$, not observed $=0$ ) within each of the eight content areas, using each of the 114 sessions as the units of analysis. There were four significant correlations $(p<.05)$ between session length and content: Discussions of contraceptive options, of how to use DMPA, of how to use barrier methods and of follow-up to the communications process were all consistently related to the length of the session. That is, the longer the counseling session, the more likely that the provider would discuss with the client the material in each of these four areas. Again, just one of these areas that proved to be sensitive to session length contained material specific to the simulated clients' chosen method.

According to the internal consistency coefficients for the summed scores (which are based on the intercorrelations between items within each area ${ }^{14}$ ), only two areasoffering the client a range of method options and describing barrier methods-are characterized by high alpha values. This suggests that the providers' behavior in these two specific content areas was highly consistent. That is, providers who talked about an individual method such as the IUD were also likely to talk about other methods such as DMPA and vaginal tablets; in contrast, providers who did not mention one particular method were less likely to address most other methods. Likewise, providers who gave clients instructions in how to use the condom were also likely to give instructions in the use of vaginal tablets. The content category of general questions, on the other hand, has a very low alpha, indicating that asking a single general question (e.g., about the client's age) did not predict whether any additional questions would also be asked (e.g., about the client's reproductive intentions).

\section{Total Information Score}

Out of a maximum score of all 46 items checked, and a minimum of 0 , the average total score was 19.2. The high internal consistency of this score-an alpha value of .84-indicates that high-achieving providers consistently performed most of the expected information-exchange behaviors, average-achieving providers consistently performed a median number, and low-performing ones consistently performed only a few. The total score was normally distributed (KolgomorovSmirnov $\mathrm{Z}=.845, \mathrm{p}<.48$, two-tailed test).

The Pearson correlation between session length in minutes and the total information-exchange score was .31 ( $\mathrm{p}<.001$, two-tailed test). Yet, the distribution of the raw session-length data was positively skewed (Kolgomorov-Smirnov Z=1.938, $\mathrm{p}<.001$, two-tailed test), which demands a closer look. Figure 1 (page 32) depicts the mean information-exchange score at each of four durations of counseling. We defined the time duration categories to reflect how the numbers of cases clustered around specific time intervals: $2-8 \mathrm{~min}-$ utes $(\mathrm{N}=22), 9-14$ minutes $(\mathrm{N}=31), 15-20$ minutes $(\mathrm{N}=38)$ and $21-45$ minutes $(\mathrm{N}=23)$.

In those counseling sessions that lasted only 2-8 minutes, providers achieved just $30 \%$ of the total possible performance score (13.6 points out of 46.0). During sessions lasting 9-14 minutes, this percentage of the maximum score increased significantly (Mann-Whitney's nonparametric test, $\mathrm{U}=153.5, \mathrm{p}<.001$, two-tailed), by $43 \%$, to reach a score of 19.4 .

Further increases in duration were as-

Table 2. Mean percentage of items on which information was exchanged for each content area, correlation between summed item scores per area and session length in minutes, and internal consistency for each area

\begin{tabular}{lccc}
\hline Content area & $\%$ & $\begin{array}{l}\text { Corre- } \\
\text { lation }\end{array}$ & $\begin{array}{c}\text { Consis- } \\
\text { tency }\end{array}$ \\
\hline General questions/offer of exam (7 items) & 56 & .09 & .12 \\
Offer of method options (8 items) & 72 & $.33^{*}$ & .76 \\
DMPA use instructions (4 items) & 53 & $.27^{*}$ & .26 \\
DMPA mechanisms of action (2 items) & 23 & .10 & .44 \\
DMPA contraindications (6 items) & 13 & .04 & .41 \\
DMPA side effects/warning signs (6 items) & 45 & .13 & .55 \\
Barrier method instructions (9 items) & 30 & $.19^{*}$ & .87 \\
Follow-up assessment (4 items) & 16 & $.26^{*}$ & .23
\end{tabular}

${ }^{*} \mathrm{p}<.05$ (two-tailed test). Notes: Correlation is measured using Pearson correlations. Consistency is measured using Cronbach's alpha. 

Figure 1. Mean number of items on which providers exchanged
information with simulated clients, by length of session

12

B

4

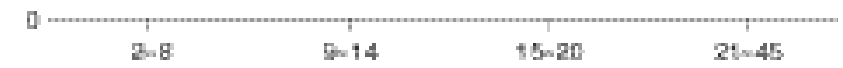

Length of session (in minutes)

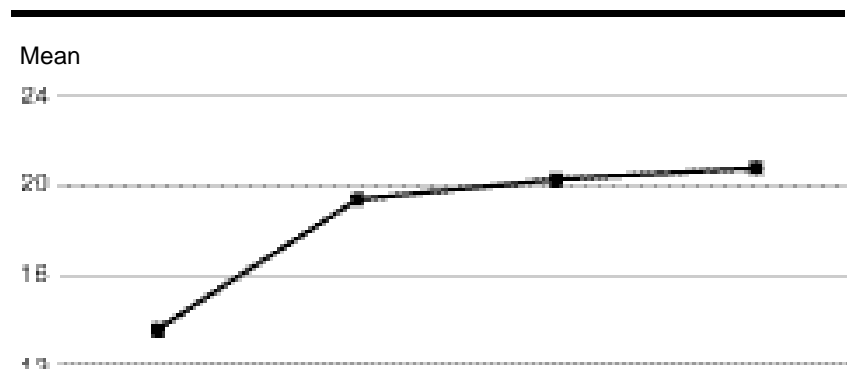

Thus, our study shows that a certain amount of providerclient interaction is needed to ensure a minimal level of information exchange: Providers made little progress in sessions lasting 2-8 minutes, while lengthening this duration to 9-14 minutes significantly increased the amount of information covered. However, extending the duration any longer than 14 minutes did not significantly improve the amount of relevant information exchanged. With more time available, providers focused on details that were ir-

sociated with smaller improvements in the total amount of information exchanged. For example, when the length of sessions increased to 15-20 minutes, the total score rose by less than $5 \%$ (nonsignificant increase), and at the maximum session length of 21-45 minutes, the total information score was still only $45 \%$ of the possible total (20.8 out of 46.0 )

\section{Discussion}

In discussions held by project supervisors with providers after the end of the project, many providers justified their omissions in counseling by pointing to time constraints; none mentioned supply shortages of DMPA or of other methods as reasons for the limited amount of specific information exchanged. Although these results confirm providers' claims that time constraints affect their performance, one important qualification emerged: Significant improvements in the amount of relevant information exchanged occurred only when sessions were lengthened to up to 14 minutes. When sessions lasted any longer, only trivial improvements occurred in the amount of useful information exchanged.

This finding cannot be attributed to individual clients tending to report specific session lengths. We analyzed the distribution of counseling session lengths to test this possibility. Of the 28 simulated clients, only two reported durations that fell within the same parameters for all of their visits (9-14 minutes in one case and 21-45 minutes in the other). The other 26 clients' estimated session lengths were distributed throughout all four levels of duration. relevant to the needs of their clients.

Our findings strongly suggest that once the client chose her method, providers dedicated little effort to addressing the chosen method again. Providers mostly ignored contraindications and did not use the increased time available to give more detailed information on the chosen method's side effects and warning signs. For example, providers' counseling more often included instructions on how to use a method that the client had no interest in (the condom) than on essential facts about the client's chosen method (such as that the next quarterly injection needed to be given within a two-week window of the scheduled date and that temporary infertility may follow DMPA discontinuation).

A number of simulated clients described the client-provider interaction as a four-step process in which the provider asked a few questions to assess the client's needs; talked about diverse method options (frequently using a flipchart); instructed the client to choose a method; and, finally, readied a supply of the method and started to discharge the client.

We would like to underscore the problems in this counseling scenario, concentrating on the inherent bias in providers' executing step 1 , and their inefficiency in handling step 2.

-Inadequate assessment of clients' needs. The questions that providers asked in step 1 of the counseling process were all medical in nature. For example, they asked about the woman's age (relevant to pill use), parity (an indicator of reproductive risk), previous contraceptive use (to reveal the client's physical tolerance to specific meth- ods) and date of last menstrual period (to rule out pregnancy).

Most providers, however, failed to ask the client basic questions about her reproductive intentions-such as whether she wanted to have more children. These women, who were instructed to report that they were relying on rhythm, were also rarely asked how they were using their method. Thus, providers' tendency to diagnose a client's contraceptive needs appears to have been influenced by habits from the past, when providers made decisions for the client, taking into account only medical criteria.

- Unnecessary presentation of all available contraceptive options. Providers behaved as though they had to describe the attributes and instructions of use for nearly all methods offered by the program. Among this full range of methods are condoms, vaginal tablets and other spermicides, the pill, DMPA, the IUD, tubal ligation, vasectomy, the implant, rhythm and lactational amenorrhea. Indeed, sessions were organized around the use of a flipchart that presented all contraceptive options. Sterilization and rhythm were excluded from most discussions, however, because of firmly entrenched preconceptions. To most providers, the calendar rhythm method is ineffective ${ }^{15}$ and sterilization is contraindicated for young women with few children.

While such a rigid implementation of step 2 may be part of an international trend, it also may be a specific reaction to scandals that afflicted the Peruvian national family planning program in the late 1990s. In 1997, human rights groups, religious activists and feminists severely criticized providers in the Ministry of Health for coercing clients to accept long-acting methods, such as sterilization. A counseling paradigm based on discussing practically all methods and then letting the client choose one for herself can hardly be regarded as coercive, yet focusing on the process of method choice detracts from focusing on the method the client has chosen.

Policy discussions centered on the need to improve the quality of family planning care stress the importance of having sufficient time for adequate counseling. Yet investing more time in counseling clients does not appear to be a viable solution to improving the quality of care in Peru's Ministry of Health facilities. In fact, about 50\% of professional providers at the ministry's health centers are now under short-term contracts with the Salud Básica para Todos (Basic Health for Everyone) project, an effort emphasizing quantitative targets that 
was instituted by the government in 1993 to improve basic health coverage. ${ }^{16}$

Moreover, the National Family Planning Program demands that all providers, not only those contracted in the Salud Básica para Todos project, complete a specified number of consultations per month and that they provide contraceptive protection to a specified number of couples each month. ${ }^{17}$ Finally, in addition to supplying family planning services, providers must attend to clients' other reproductive and maternal health needs, and perform a number of administrative functions. Faced with these demands, providers are unlikely to increase the length of sessions spent discussing family planning with each client.

Nonetheless, the ministry's family planning program can improve its service provision paradigm so that providers use their available time more efficiently. Presently, the program's trainers use a model called the "Five Steps of Counseling"18 that endorses the following steps: establish a warm relation with the client; identify the client's needs; respond to those needs; verify that the client has understood; and maintain a cordial relationship with the client.

The guidelines in steps 2 and 3 are especially vague. An improved counseling model would specify that instead of focusing the needs assessment on strictly medical issues, providers should use a more practical approach that takes into account the client's (and her partner's) beliefs and attitudes that influence method choice. Also, instead of talking in detail about most methods, providers should focus on the few methods that are really relevant to the client's situation. The time saved in discussions that precede the client's choice could then be invested more efficiently in advice on issues specific to the method chosen (i.e., screening the client for contraindications to that method and explaining how to use it, along with its side effects and warning signs).

Several caveats warrant mention, however. First, the simulated clients did not time the counseling sessions but estimated their length instead. We believe that although possible errors in the calculation of session length could have affected the exact data reported here (such as the 14minute cut-off point discussed above), such errors would not alter the essential relationships found in the study.

Second, the client profile enacted by the simulated clients indicated the choice of DMPA, a method that is easier to provide than is either the pill or the IUD (i.e., it has comparatively fewer user instructions, side effects and contraindications). If clients were to choose the pill or the IUD, however, their counseling sessions might increase in length, but otherwise the findings should not be expected to be substantially different.

A third word of caution concerns the fact that out of a possible score of 46 items, providers, on average, covered only 19.2. This finding does not necessarily reflect badly on the overall quality of family planning care offered in Ministry of Health facilities. The service test is a stringent evaluation methodology that focuses on very specific provider behaviors. For example, its instrument verifies the presence (one point), as opposed to the absence (zero points), of a mention of each relevant side effect; other tools, however, such as the Tulane observation instrument, ${ }^{19}$ focus on the mention of any side effect at all (i.e., one point for the mention of any side effect and zero points only if no single side effect is mentioned). The service test and the Tulane instruments are therefore not strictly equivalent, and the service test will necessarily produce poorer results.

Currently, the Peruvian Ministry of Health is experimenting with a reformulated counseling strategy in selected health centers that emphasizes a more balanced handling of the situation by the provider-that is, less time is spent on helping clients choose a method, basically by avoiding irrelevant topics, which allows more time to be dedicated to the method chosen. ${ }^{20}$ We suspect that the counseling trends found in this study in Peru probably prevail in other countries and that their family planning programs might thus also benefit from introducing similar solutions.

\section{References}

1. Bruce J, Fundamental elements of the quality of care: a simple framework, Studies in Family Planning, 1990, 21(2):61-91.

2. Kim YM, Kols A and Mucheke S, Informed choice and decision-making in family planning counseling in Kenya, International Family Planning Perspectives, 1998, 24(1):4-11.

3. Mensch BS et al., Family planning in Nairobi: a situation analysis of the City Commission clinics, Interna tional Family Planning Perspectives, 1994, 20(2):48-54.

4. Miller $\mathrm{K}$ et al., Clinic-Based Family Planning and Reproductive Health Services in Africa: Findings from Situ ation Analysis Studies, New York: Population Council, 1998.

5. Bertrand JT, Prueba de campo conducida en varios países sobre indicadores de calidad de atención en programas de planificación familiar en clínicas, paper presented at the Visitor Conference at the Population Council, Lima, June 17, 1999

6. Cáceres C and Villanueva E, Comportamiento delproveedor en la consulta de planificación familiar, in León
FR, ed., Quality of care and user outcomes in the province of Santa, Peru: 1. a diagnostic study with focus on providers, Final Report of INOPAL IIISub-Project,Lima: Population Council, 1997.

7. León FR et al., Developing algorithmic instruments to help providers and users to implement the new reproductive health care guidelines issued by the Ministry of Public Health of Ecuador, Final Report of INOPAL III Sub-Project, Lima: Population Council, 1998.

8. León FR et al., Mejorando la Calidad y Acceso a Servicios de Planificación Familiar en Ambitos Rurales y Semi-Rurales del Perú, Lima: Instituto Andino de Demografía y Población, 1994.

9. Ramos I and Wong L, Soluciones discutidas con los proveedores, in León FR, 1997, op. cit. (see reference 6).

10. León FR, Peru: provider's compliance with quality of care norms, Final Report of FRONTIERS Project, Lima: Population Council, 1999.

11. León FR et al., 1994, op. cit. (see reference 8).

12. Peru Ministry of Heath, Family Planning Program, 1998 Family Planning Service Statistics.

13. Manual de Salud Reproductiva: Métodos y Procedimien tos, Lima: Ministerio deSalud del Perú, 1992, pp. 95 \& 99.

14. Cronbach L, Coefficient alpha and the internal structure of tests, Psychometrika, 1951, 16:297-334.

15. Snowden R et al., Physicians' views of periodic abstinence methods: a study in four countries, Studies in Family Planning, 1988,19(4):215-226.

16. Parra J, Peru National Family Planning Program, Lima, personal communication, Dec. 12, 2000.

17. Ibid.

18. Manual de Normas y Procedimientos para Consejería en Planificación Familiar, Lima: Ministerio de Salud, 1998.

19. Miller K et al., 1998, op. cit. (see reference 4); and Bertrand JT, 1999, op. cit. (see reference 5).

20. León FR, Provider and client impacts of an intervention designed to improve the provider-client interaction in Ministry of Health clinics in Peru, FRONTIERS Operations Research Project Proposal, Lima: Population Council, May 31, 2000.

\section{Resumen}

Contexto: Las limitaciones de tiempo han repercutido en la capacidad de los proveedores de los servicios de planificación familiar para ofrecer consejería integral a sus clientas. Es importante que los proveedores sepan si la duración de las sesiones de consejería aumentan la cantidad de información relevante que se les imparten a sus clientas.

Métodos: Se adiestró a 28 mujeres para que pretendieran solicitar un método anticonceptivo eficaz y que optaran por el inyectable en 19 clínicas urbanas que formaban parte de una muestra nacional de clínicas del Ministerio de Salud del Perú. Cada clínica fue visitada en un día diferente por una de estas seis "supuestas clientas", lo cual ascendió a un total de 114 casos. En cada visita las mujeres registraron los temas tratados con sus consejeros en una lista de 46 tópicos y estimaron la duración de tiempo de la sesión.

Resultados: Los proveedores dedicaron entre dos y 45 minutos a cada sesión. La cantidad (continued on page 46) 


\section{Length of Counseling...}

(continued from page 33)

de información transmitida a las clientas varió significativamente y aumentó en un $43 \%$ cuando las sesiones aumentaban de 2-8 $\mathrm{mi}$ nutos a 9-14 minutos de duración. Sin embargo, cuando las sesiones se prolongaban más allá de los 14 minutos el aumento en la cantidad de información útil recibida era muy pequeño o no significativo. Fuere cual fuere la duración de la sesión, muchos datos que deberían haber sido transmitidos no lo fueron. La mayor parte de la consulta se utilizó para ofrecer una amplia gama de métodos anticonceptivos, y ello incidió en la duración de la sesión. No variaban por la duración de sesión las discusiones sobre los efectos secundarios del método y el tamizaje por la presencia de las contraindicaciones a su uso.

Conclusiones: Las sesiones de consejería de más de 14 minutos ofrecen pocas ventajas en cuanto a su eficacia. Es importante evitar la transmisión de demasiada información sobre métodos irrelevantes. Los proveedores deben utilizar estrategias de consejería que se centren en el método anticonceptivo elegido por la clienta y que enfatizan los asuntos relacionados con ese método específico en forma minuciosa.

\section{Résumé}

Contexte: Les contraintes de temps ont étécitées parmi les causes de l'inaptitude des prestataires de planning familial à assurer des services de consultation complets à leur clientèle. Il est important de savoir si l'assurance de séances de consultation plus longues peut accroître la quantité d'informations pertinentes communiquées aux clientes.

Méthodes: Vingt-huit fermmes ont été formées au rôle de clientes en quête d'une méthode efficace finissant par choisir la méthode injectable dans 19 cliniques urbaines d'un échantillon national du ministère péruvien de la Santé publique. Six de ces "clientes simulées» se sont rendues, à différentes dates, dans chaque clinique, pour un total de 114 cas. A chaque visite, la femme devait consigner sur une liste composée de 46 entrées les questions abordées par le prestataire et la durée estimée de la consultation.

Résultats: Les prestataires se sont avérés consa- crer deux à 45 minutes à la consultation. La quantité d'informations pertinentes au choix de la cliente s'est révélée supérieure, de 43\%, lors des séances de 9 à 14 minutes, par rapport à celles de 2 à 8 minutes. Au-delà de 14 minutes, l'amélioration quantitative des informations utiles échangées était toutefois négligeable et non significative. Quelle que soit la durée de la consultation, de nombreuses informations importantes n'ont pas été communiquées. L'offre d'un large éventail d'options contraceptives occupait la plus grande partie de la consultation, en corrélation élevée avec la durée de la séance. La longueur de la consultation s'est révélée sans effet sur la discussion des effets secondaires de la méthode choisie et l'identification des contre-indications éventuelles.

Conclusions: Les séances de plus de $14 \mathrm{mi}$ nutes n'offrent guère d'avantages, en termes d'efficacité de la consultation. Il importe d'éviter l'offre d'informations excessives au sujet des méthodes non pertinentes. Il convient pour les prestataires d'adopter des stratégies de consultation concentrées sur la méthode choisie par la cliente et de discuter cette méthode de manière plus approfondie. 